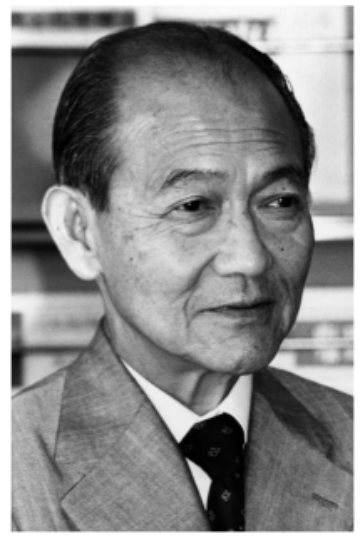

Susumu Hibino, MD

1908-2005

\title{
A Tribute to the Memory of Susumu Hibino, MD
}

Int J Hematol. 2005;82:175. doi: 10.1532/IJH97.882005

(C)2005 The Japanese Society of Hematology

Dr. Susumu Hibino, one of the most distinguished members of the International Society of Hematology, died on June $16,2005,2$ days short of his 97 th birthday. He was the only surviving member of those who founded the Japanese Society of Hematology in 1937 and started the official Journal of our Society, Acta Haematologica Japonica (currently International Journal of Hematology). He has made outstanding contributions to the field of hematology during the past 70 years.

Born in Gifu, Japan, Dr. Hibino was graduated from Aichi Medical School in 1931 and joined the Department of Medicine to begin his career in medical research under late Professor Seizo Katsunuma. Needless to say, this was an era when the Internal Medicine was not yet as narrowly differentiated as today, so Dr. Hibino began studies of various diseases, including tuberculosis, typhoid fever, pneumonia, beriberi, anemia, leukemia, lupus and Friedreich's ataxia. After serving as a physician in the Imperial Army and after World War II, he returned to Nagoya University School of Medicine, and succeeded Dr. Katsunuma to become Professor and Chairman of the First Department of Medicine from 1949 to 1968. During the 19-year tenure in this post he built a strong Department of Medicine. Among others, hematology-oncology was one of his favorites and he encouraged many young physicians to study blood diseases. $\mathrm{He}$ has played a leading role in the development of the diagnosis and management of leukemia, aplastic anemia, and related disorders. In particular, he and his group introduced in the early 1960s the concept of multidrug combination chemotherapy into the treatment of acute leukemia and founded the basis for long-term survival in the previously fatal disease. He also contributed significantly to the understanding of the pathogenesis and pathophysiology of aplastic anemia.
Dr. Hibino assumed a strong international leadership in the promotion of hematology. In as early as 1958 he established the Asian Society of Hematology, which later evolved into the Asian-Pacific Division of the International Society of Hematology (ISH-APD) - one of many examples illustrating that he was a leader, far ahead of his times. He served as Secretary-General of the APD from 1960 to 1972 and was Vice-President from 1972 to 1976.

During his long productive years and also after retirement, Dr. Hibino remained a keen observer and clear thinker. He regularly attended the Annual Meeting of the Japanese Society of Hematology and attentively listened in the front row to the presentations of young hematologists. In addition to medicine, Dr. Hibino had deep affection for the history of medicine and Japanese poetry, Haiku. His last years were as intellectually active as those previously. Even in his 90s, when his body had become frail, his wit, his memory, and his shrewd insight continued to highlight his personality among all friends and students. As a skilled clinician he believed in and stressed to us the importance of physician's good manners, for example, by dressing himself up even during hot, humid, exhausting summer days in Nagoya, with a necktie, a long-sleeve shirt, and a jacket.

With his death, our Society has lost a legendary leader and administrator, and many of us lost a great mentor who inspired us.

Hidehiko Saito, MD

Secretary-General, Asian-Pacific Division of the

International Society of Hematology

Nagoya Medical Center

Nagoya, Japan 